\title{
Health Self-Management Skill and its Predictors among Elderly Female Empty Nesters in China
}

\author{
Shuang Qin Chen ${ }^{1}$, Zhi Xia Zhang*2 and Ji Er Su${ }^{1}$ \\ ${ }^{1}$ School of Nursing, NingBo College of Health Sciences, PR China \\ ${ }^{2}$ Nursing Department, Linfen Fourth People's Hospital, PR China \\ *Corresponding author: Zhi Xia Zhang, Nursing Department, Linfen Fourth People's Hospital, PR China
}

ARTICLE INFO

Received: 幽 March 25, 2019

Published: March 29, 2019

Citation: Shuang Qin Chen, Zhi Xia Zhang, Ji Er Su. Health Self-Management Skill and its Predictors among Elderly Female Empty Nesters in China. Biomed J Sci \& Tech Res 16(4)-2019. BJSTR. MS.ID.002876.

Keywords: Elderly Empty Nester; Female; Health Self-Management Skill; Sense of Coherence

\section{ABSTRACT}

Aim: To investigate the level of health self-management skill and identify associated factors among elderly female empty nesters.

Methods: There were 372 female elderly empty nesters from five communities in the city of Ningbo in China included in the study. They were recruited by convenience sampling between April and October 2017. A demographic data questionnaire, the Sense of Coherence- 13 questionnaire, and the Health Self- management Skill Scale for Adults were used to collect data.

Results: The mean sense of coherence score was $57.64 \pm 11.35$, which was low. The mean health self-management skill score was $125.64 \pm 20.22$, with the highest mean score per item for the cognition dimension and lowest for the behavior dimension. Sense of coherence and having more comorbidities were associated with better self-management behavior. Educational level, having more comorbidities, and religious beliefs were associated with better self- management cognition. Sense of coherence and not living alone were associated with better self-management environment.

Conclusion: Community workers should pay attention to the management of female elderly empty nesters, expand their social contacts, encourage and guide them to use all kinds of social resources to solve their difficulties, improve data collection concerning elderly living alone, establish periodic condolences and a follow-up system, and improve their health self-management skill.

\section{Introduction}

With the dramatic increase in China's elderly population, the number of elderly empty nesters (i.e., parents whose children have grown up and left home) has increased dramatically. According to estimates, this group will increase to more than 200 million by 2030 , accounting for $90 \%$ of the total elderly population [1]. Focusing on the physical and mental health of elderly empty nesters has become recognized as an important topic for building a harmonious society [2]. Additionally, the gender differences in physical and mental health and quality of life among elderly empty nesters have attracted increased attention from researchers in recent years. According to surveys, compared with male elderly empty nesters, female elderly empty nesters lose their physical labor ability earlier and have lower income, less security, lower participation in social activities [3], increased lack of physical and mental health [4], and significantly poorer quality of life [5].

Health self-management skill is an individual's ability to manage their own health, which comprises three aspects: selfmanagement behavior, self-management cognition, and selfmanagement environment [6]. Health self-management is a new aspect of health promotion that can help individuals to maintain the best health state by adopting healthy behaviors and cognition, thereby helping people to change their unhealthy lifestyles and form healthy behaviors. It can significantly improve the quality of life of the elderly and promote healthy aging [7]. More and more 
researchers have shifted their research focus from negative health factors to beneficial factors, and also to how individuals used their own internal resources to cope with stressors in order to maintain their physical and mental health. The Salutogenic theoretical Mode, proposed by Antonovsky [8], has played an important role in promoting the development of positive psychology. The Salutogenic theoretical Mode focuses on ways for people to maintain and promote their health, not only on the prevention and mitigation of diseases. In other words, the focus had shifted from risk factors to beneficial factors.

In the Salutogenic theoretical Mode, Sense of Coherence (SOC) is a core concept. SOC is a person's view of life and capacity to respond to stressful situations. It comprehensively reflects an individual's perception of the internal and external environment, the perception of the resources they have to cope with stress, and the meaning of life. It also assesses the general and dynamic sense of confidence that an individual has to cope with stress [9]. Research has confirmed that SOC is positively correlated with optimism, self-behavior management, and positive coping [10], and it is an important predictor of quality of life [11]. This predictive value was greater for women than for men, and women were affected by their SOC level much earlier than men [12]. It has been shown that individuals with a high SOC can make rational use of the resources around them, actively cope with stress, and have better self-management behavior [13]

Previous studies have also shown that the main factors influencing health self-management are demographic factors, socio-economic factors, and health status. Demographic factors, including age, marriage status, and educational level, have been shown to have an important impact on health self-management. In the Survey on the Status and Influencing Factors of Adult Health Self-Management Skill by Huang et al. [14], the score for the elderly was higher than those for the young and middle-aged, which was consistent with research by Wang and Cao [15]. The elderly, who tend to have deteriorating bodily function and increasing numbers and severity of diseases, pay more attention to their health. In contrast, the young do not, as they often have no obvious symptoms of discomfort and neglect any health problems.

Socio-economic factors include monthly income and medical security. A good economic situation tends to be a prerequisite for good health self-management. Lopez-Class and Jurkowski [16] showed that the better the economic situation, medical security, and other support, the higher the health self-management level. This fits with Maslow's demand theory. Elderly individuals with medical security have better economic conditions that allow them to learn health self-management skill and pay more attention to health care and health preservation. The poor need first to meet their needs related to their daily lives and any urgent medical treatment required, neglecting the higher-level aspects of life.

Health status, including the presence of any illnesses, type of illness, and degree of illness, directly affects health self-management.
Simpson and Rocker [17] showed that self-management skill was better for those with good rather than poor health status. The better the health status, the more individuals exhibited active health promotion behavior and motivation for health selfmanagement. Individuals with poor health tended to consider it to be too late to take positive action. Thus, we combined relevant demographic variables (highlighted in the empirical literature) and SOC to investigate correlates of health self-management skill among Chinese female elderly empty nesters. The main purpose of this study was to investigate the level of SOC and health selfmanagement skill among female elderly empty nesters and analyze the relationship between them.

\section{Methods}

\section{Participants and Data Collection Procedure}

From April 2017 to April 2018, using convenience sampling, we selected five communities in the city of Ningbo in China as the research sites. Female elderly empty nesters in these communities were selected as the research population. The inclusion criteria were as follows:

a) Age $\geq 60$ years old;

b) No children or children but had not lived with them for $>1$ year;

c) Good awareness and normal ability to communicate with investigators; and

d) Voluntary participation in this study.

The exclusion criteria were as follows:

\section{a) Psychiatric history and}

b) Severe physical disease (including advanced cancer) or disability or Alzheimer's disease. The patients who fulfilled the inclusion and exclusion criteria were interviewed using structured questionnaires by trained research assistants. A total of 388 individuals were enrolled in the survey study. However, 16 subsequently refused to participate because they lost interest or experienced physical discomfort, which resulted in a total of 372 female elderly empty nesters (95.9\% response rate).

The first author contacted the neighborhood offices of the five communities, obtained their consent and cooperation. Then a survey team was established, and the training for the members of the survey team that included details on the study purpose, the attention in filling out the questionnaire, and an assurance of anonymity before the survey was confirmed. Questionnaires were distributed by means of household visits and in-depth visits to local gathering places (parks, squares, elderly activity centers, etc.). Before issuing each questionnaire, the subject's oral informed consent was obtained. The questionnaire was collected after 30 minutes and its completeness was checked on the spot. For individuals with literacy problems or visual impairments, the 
questions were asked verbally and the answers were recorded in the questionnaire by the investigators.

\section{Measures}

Demographic Data Questionnaire: The demographic data questionnaire collected data on age, education level, whether the participant lived alone, number of children, average family monthly income, religious beliefs, medical expenses, whether the participant had a comorbidity, and the number of comorbidities.

Sense of Coherence-13 (SOC-13): Antonovsky [18] developed this scale to assess girls' overall feelings about and perceptions of life. Bao and Liu [19] adapted the questionnaire to fit with Chinese culture, which involved revising it and conducting cross-cultural debugging. The Chinese version of the scale contains 13 items in three dimensions: comprehensibility (5 items), controllability (4 items), and sense of meaning ( 4 items). Items are scored using a 7-point Likert scale. The range of the total score is 13-91. The higher the score, the higher the individual's SOC. Scores were categorized as low (13-63), medium (64-79), or high (80-91) [20]. The scale has been shown to have good reliability and validity in the Chinese population $[10,19]$.

Health Self-management Skill Scale for Adults: This scale was constructed by Zhao and Huang (2011) at the School of Nursing, Harbin Medical University, based on Bandura's social cognitive theory. The scale contains 38 items in three dimensions: health self-management behavior (14 items), health self-management cognition (14 items), and health self-management environment (10 items). Items are scored using a Likert scale. The higher the score, the higher the individual's health self-management skill. The scale has been shown to have good reliability and validity in the elderly population in China [21,22].

\section{Statistical Analyses}

The data were imported into Epidata 3.0 software and then into SPSS 20.0. The data displayed normal distribution before data analysis. Therefore, we used parametric statistical analysis in this study. Descriptive statistics (frequency distribution, percentage, means, SDs) were used to analyze demographic data, level of health self-management skill and sense of coherence of female empty nest elderly. Multivariate stepwise regression analysis was used to analyze the variables (Sense of coherence and demographic characteristics) associated with health self-management skill among female elderly empty nesters.

\section{Results}

\section{Subject Characteristics}

The subjects were 60-76 years old (66.32 \pm 5.29$)$; 58 had a junior high school level of education (46.8\%); 23 lived alone (18.5\%); 61 had one child (49.2\%); 49 were retired (39.5\%); and 69 had an average family monthly income of $<1,000$ yuan (55.6\%).

\section{SOC Level of Female Elderly Empty Nesters}

As shown in Table 1, the mean SOC score of the female elderly empty nesters was 57.64 \pm 11.35 , which was low. Among them, 61 individuals had low SOC (49.2\%), 41 had medium SOC (33.1\%), and 22 had high SOC (17.7\%). The mean scores per item in each dimension indicated that the comprehensibility dimension had the highest score and the sense of meaning dimension had the lowest score.

Table 1: Sense of Coherence scores among 372 female elderly empty nesters scored.

\begin{tabular}{|c|c|c|}
\hline Dimension & $\begin{array}{c}\text { Total score (mean } \pm \\
\text { SD) }\end{array}$ & $\begin{array}{c}\text { Mean score per item } \\
\text { (mean } \pm \text { SD) }\end{array}$ \\
\hline Comprehensibility & $24.02 \pm 4.53$ & $4.83 \pm 0.96$ \\
\hline Controllability & $17.10 \pm 3.46$ & $4.32 \pm 0.94$ \\
\hline Sense of meaning & $16.52 \pm 3.67$ & $4.16 \pm 0.87$ \\
\hline Total & $57.64 \pm 11.35$ & $4.47 \pm 0.97$ \\
\hline
\end{tabular}

\section{Health Self-Management Skill Level of Female Elderly Empty Nesters}

As shown in Table 2, the mean health self-management skill score of female elderly empty nesters was $125.64 \pm 20.22$. The mean scores per item indicated that the self-management cognition dimension had the highest score and the self-management behavior dimension had the lowest score.

Table 2: Health self-management skill scores among 372 female elderly empty nesters.

\begin{tabular}{|c|c|c|}
\hline Dimension & Total score (mean \pm SD) & Mean score per item (mean \pm SD) \\
\hline Behavior & $43.06 \pm 6.75$ & $3.08 \pm 0.51$ \\
\hline Cognition & $51.42 \pm 8.03$ & $3.69 \pm 0.67$ \\
\hline Environment & $31.16 \pm 5.89$ & $3.15 \pm 0.58$ \\
\hline Total & $125.64 \pm 20.22$ & $3.32 \pm 0.68$ \\
\hline
\end{tabular}

Multivariate Analysis of Factors Associated with Health Self-Management Skill among Female Elderly Empty Nesters

SOC and comorbidity were associated with better self-manage- ment behavior; educational level, comorbidity, and religious beliefs were associated with better self-management cognition; and SOC and not living alone were associated with better self-management environment, as shown in Table 3. 
Table 3: Multivariate regression analysis of factors associated with health self-management skill among 372 female elderly empty nesters.

\begin{tabular}{|c|c|c|c|c|c|c|}
\hline $\begin{array}{l}\text { Health self- } \\
\text { management } \\
\text { dimension }\end{array}$ & Independent variable & $\begin{array}{l}\text { Regression } \\
\text { coefficient }\end{array}$ & Standard error & $\begin{array}{c}\text { Standardized regression } \\
\text { coefficient }\end{array}$ & $t$ & $\boldsymbol{P}$ \\
\hline \multirow{3}{*}{ Behavior (Y1) } & Constant & 5.952 & 3.424 & & 5.738 & 0.000 \\
\hline & Sense of Coherence (SOC) & 3.876 & 1.231 & 0.327 & 4.107 & 0.000 \\
\hline & Comorbidity & 2.436 & 0.958 & 0.274 & 2.438 & 0.021 \\
\hline \multirow{4}{*}{ Cognition (Y2) } & Constant & 6.125 & 3.061 & & 4.920 & 0.000 \\
\hline & Educational level & 4.204 & 1.482 & 0.304 & 3.792 & 3.792 \\
\hline & Comorbidity & 2.671 & 1.023 & 0.252 & 2.126 & 0.023 \\
\hline & Religious beliefs & 1.796 & 0.824 & 0.249 & 1.947 & 0.030 \\
\hline \multirow{3}{*}{ Environment (Y3) } & Constant & 7.218 & 3.784 & & 6.091 & 0.000 \\
\hline & Sense of Coherence (SOC) & 4.280 & 1.569 & 0.374 & 4.594 & 0.000 \\
\hline & Not living alone & 2.729 & 0.938 & -0.281 & -2.558 & 0.019 \\
\hline
\end{tabular}

Note: Self-management behavior model: $\mathrm{R}^{2}=0.493$, Delta $\mathrm{R}^{2}=0.442, \mathrm{~F}=19.65, \mathrm{P}<0.01$; self-management cognition model: $\mathrm{R}^{2}=0.522$, Delta $R^{2}=0.495, F=23.37, P<0.01$; self-management environment model: $R^{2}=0.418$, Delta $R^{2}=0.386, F=15.51, P<0.01$.

\section{Discussion}

The SOC of female elderly empty nesters was low. SOC is the core concept of the Salutogenic Mode, which emphasizes the protection and promotion of mental health based on an individual's stress-resistant resources. In this study, the mean SOC score of female elderly empty nesters was $57.64 \pm 11.35$, which was lower than the results in previous studies on elderly individuals $[10,20]$. The current study showed that the female elderly empty nesters had low confidence in their physical and mental health and their improvement. The reasons might be related to the following two points. First, previous research had shown that female elderly empty nesters tend to have low social participation, a general apathy towards politics, and extremely limited spiritual and cultural lives $[3,4]$. Low social participation may reduce their number of sources of knowledge, so they have access to even fewer available resources. Second, the average life expectancy of Chinese women has always been longer than that of men. Thus, the older the age group, the higher the proportion of females. Research has shown that although the life expectancy of women is long, their physical health tends to be good [23].

However, the health situation has been shown to be worse among women than that among men of the same age. The incidence rate of major diseases and disabilities has been shown to be significantly higher among women than among men of the same age [23]. Having long-term poor physical health status could weaken confidence in health self-management among female elderly empty nesters. In this study, the mean scores per SOC item decreased from the comprehension dimension, to the controllability dimension and lastly to the sense of meaning dimension. These three SOC questionnaire components correspond to the cognitive, instrumental, and motivational components of SOC, respectively [20]. Thus, we showed that female elderly empty nesters had a good understanding of their current situation and could understand the advantages and disadvantages of their situation, but they had poor motivation and low confidence regarding changing the situation. Therefore, community workers should provide female elderly empty nesters with broad social activities, expand their social participation, encourage and guide them to make use of various social resources, and help them to make appropriate adjustments in their family environment to improve their SOC.

The health self-management skill of female elderly empty nesters was poor. The mean health self-management skill score of female elderly empty nesters was $125.64 \pm 20.22$, which is considerably lower than the results of previous surveys [6,24]. The highest mean score per item was for the self-management cognition dimension, and the lowest was for the self-management behavior dimension, which indicated that health self-management skill among the female elderly empty nesters had a clear "high cognition, low behavior" presentation. This result was the same as the result reported by Feng [7], who surveyed elderly individuals in Hebei Province. With societal progress, many elderly people's perceptions, concepts, and attitudes toward health have changed considerably, but some also have limitations regarding their cognitive level. In this study, they seldom take targeted action regarding diet, medicine, sports management, and so on. Health education for female elderly empty nesters should be gradually improved, from simple health education to education on how to convert knowledge into behavior.

In the multivariate regression analyses, SOC was associated with health self-management behavior and self-management environment among the female elderly empty nesters. The higher the SOC, the better the self-management behavior and self-management environment. SOC is an intrinsic resource for individuals when facing stress. Studies $[9,25]$ had shown that positive experience regarding stress was significantly greater in individuals with high SOC than in individuals with low SOC. 
Additionally, individuals with high SOC were more likely to recover from negative emotions and had a greater ability to cope with setbacks. Individuals with high SOC have a positive and predictable overall attitude toward life, and can better understand and analyze themselves and stress events [26]. In this study, the female elderly empty nesters with high SOC had more positive motivation for learning and good ability to cope with setbacks, and they tended to respond positively to setbacks in the process of health management learning and self-behavior management. In addition, these individuals could better understand and utilize the support system around them, and more confidently use the resources obtained to cope with stress [20].

Therefore, community workers should guide female elderly empty nesters to face the pressures of aging and diseases with a peaceful attitude, encourage and guide them to use all available resources to face challenges in life, and discuss the possible difficulties and self-management coping styles with them, so as to improve their self-management behavior and self-management environment. Other factors associated with health self-management skill of the female elderly empty nesters included comorbidity. The higher the number of comorbidities was combined, the better their self-management behavior. The elderly has a high risk of developing various comorbidities due to deterioration in physical function. Cardiovascular diseases, diabetes mellitus, and lung diseases were common comorbidities in the elderly in this study. The existence of a comorbidity impairs the elderly's physical health and causes great inconvenience in their daily lives, but it also promotes paying attention to diet, exercise, timely medical treatment, and other behaviors [24]. Therefore, female elderly empty nesters with comorbidities had better health self-management behavior.

Educational level, comorbidity, and religious beliefs were associated with the health self-management cognition of the female elderly empty nesters. The higher the education level, the higher the learning ability and the higher the income of female elderly empty nesters [27]. Good learning ability and socioeconomic status promote learning about health management and increase their health self-management cognition. The female elderly empty nesters with comorbidities, as mentioned above, may pay attention to related knowledge because of their health status, so health selfmanagement cognition was better. The participation in religious activities and rituals could help the female elderly empty nesters to achieve a state of calm and spiritual comfort. Some researchers believe that religious participation can help individuals gain more social support, reduce their assessment of stress levels and threats of negative events, and promote positive perceptions of stress events [28]. Therefore, female elderly empty nesters with religious beliefs were likely to be more proactive in understanding and recognizing the physical health problems caused by diseases and aging, which might be the reason for their higher health selfmanagement cognition.
The health self-management environment of the elderly empty nesters living alone was poor. A good health self-management environment includes health resource utilization and environmental self-management. Compared with other elderly empty nesters, the health and economic status of the elderly living alone were often worse and, as shown by a previous study, elderly individuals living alone tend to have a lack of care and be more likely to have negative emotions such as depression [29]. Another study showed that social communication and social support were also significantly lower among the elderly living alone than among the elderly not living alone [30]. These factors can lead to the decreased utilization of health resources. In addition, the elderly empty nesters living alone were often unable to perceive the physical health changes in time, and few people took proper care of themselves. They tended to have a poor ability to manage their living environment [30-32]

Elderly people living alone in empty nests need care from all sectors of society. Relevant community workers should strengthen the construction of community organizations, establish improved data collection concerning the elderly living alone, establish suitable regular condolences and door-to-door follow-up systems, and improve the care of the elderly empty nesters living alone.

\section{Limitations of the Study}

This study has several limitations. In particular, we used convenience sampling to collect data, which may have decreased the representativeness of the sample. Thus, we could not fully describe the characteristics of health self-management skill in all female elderly empty nesters.

\section{Conclusion}

To sum up, the SOC of the female elderly empty nesters was low, and their health self-management skill was poor. Community workers should pay attention to the care of female elderly empty nesters, provide them with broad social activities, expand their social participation, encourage and guide them to use various social resources to face difficulties in life, establish improved data collection concerning the elderly living alone, and establish regular condolences and suitable door-to-door follow-up systems to improve the health self-management skill of female elderly empty nesters.

\section{Acknowledgement}

Funding for this study was provided by Ningbo Collaboration and Innovation Center for Health for Aged-care, China (Grant no. NBYL201606 and Grant no. JKYL201807). We would like to thanks the nurses in the tertiary hospital for their assistance with data collection and to all the women with breast cancer who took part in the study.

\section{References}

1. Wang LN, Su H, Li SS, Yao JL, Zhou YQ (2016) Development of empty-nest elderly mental health self-help ability scale and testing of its reliability and validity. Chinese General Practice 19: 4379-4384. 
2. Li YY, Gao M, Zhang WJ, Tian DH (2017) Is empty nest a risk for the health of urban elderly? Population Journal 39(5): 4379-4384.

3. Zeng YC (2016) A research on the pension status of the female rural empty nest elderly in the view of social gender take the Village D, Country N, Nanchang, Jiangxi for example. Nanchang, Jiangxi Agricultural University.

4. Zhao JL (2012) Rural aged women's disadvantages in social security from the social gender perspective-take Shandong Province as an example. Ningxia Journal of Agriculture and Forestry Science and Technology 53: 54-57.

5. Huang J, Huang L (2012) An investigation \& research of survival quality of the rural empty nest elderly women in the Three Gorges reservoir area. Journal of Chongqing Three Gorges University 28: 24-28.

6. Zhao QL, Huang FF (2011) Development and the reliability and validity test of the rating scale of health self-management for adults. Chinese Journal of Modern Nursing 17: 869-872.

7. Feng LN (2015) Status and influential factors of health self-management of the elder in Hebei areas. Tangshan, North China University of Science and Technology.

8. Antonovsky A (1987) Unraveling the mystery of health: How people manage stress and stay well. San Francisco Jossey-Bass, pp. 195-209.

9. Xi T, Zhang ZM, Xiao ZP, Lei YY (2014) The current situation and prospects of research on sense of coherence. China Journal of Health Psychology 22: 151-155.

10. Guo LN, Liu YC, Liu K (2016) The mediating effect of psychological coherence on psychological stress and depressive symptoms in the elderly. Chinese Journal of Practical Nursing 32: 443-445.

11. Gotay CC, Isaacs P, Pagano I (2010) Quality of life in patients who survive a dire prognosis compared to control cancer survivors. Psychooncology 13: 882-892.

12. Wrześniewski K, Włodarczyk D (2012) Sense of coherence as a personality predictor of the quality of life in men and women after myocardial infarction. Kardiol Pol 70: 157-163.

13. Stein Parbury J, Gallagher R, Chenoweth L, Luscombe GM (2012) Factors associated with good self-management in older adults with a schizophrenic disorder compared with older adults with physical illnesses. J Psychiatr Ment Health Nurs 19: 146-153.

14. Huang FF, Zhao QL, Guo MY, Tian XX (2011) The level and influencing factors of health self-management skill in adults. Chinese Journal of Nursing 46: 701-704

15. Wang X.W, Cao YJ (2008) Investigation on health behaviors of middleaged and aged people in community. Chinese Nursing Research 22 1524-1525.

16. Lopez-Class M, Jurkowski J (2010) The limits of self-management: Community and health care system barriers among Latinos with diabetes. J Hum Behav Soc Environ 20: 808-826.

\section{ISSN: 2574-1241}

\section{DOI: 10.26717/BJSTR.2019.16.002876}

Zhi Xia Zhang. Biomed J Sci \& Tech Res

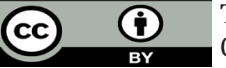

This work is licensed under Creative Commons Attribution 4.0 License

Submission Link: https://biomedres.us/submit-manuscript.php
17. Simpson AC, Rocker GM (2008) Advanced chronic obstructive pulmonary disease: Rethinking models of care. QJM 101: 697-704.

18. Antonovsky A (1993) The structure and properties of the sense of coherence scale. Soc Sci Med 36: 725-733.

19. Bao LP, Liu JS (2005) The reliability and validity of Chinese version of SOC-13. Chinese Journal of Clinical Psychology 13: 399-401.

20. Li ZY (2017) The mediating effect of coping styles between sense of coherence and self-management behaviors in elderly patients with coronary heart disease. Qingdao, Qingdao University.

21. Feng LN, Chen CX (2014) The correlation between socioeconomic status and health self-management in elderly people. Chinese Journal of Nursing 49: 1303-1307.

22. Cheng XD (2017) Influence of health self-management ability on life quality of elderly patients with chronic disease in country. China Modern Medicine 24: 174-177.

23. Wu LP (2011) The research of the problem of community service for elderly women in Xi' an from the perspective of harmonic society. Xi'an, Xi'an University of Architecture and Technology.

24. Zhang AH (2016) Survey on health self-management ability and selfrated health status of elderly patients with chronic diseases. Journal of Qi Lu Nursing 22: 43-44.

25. Cai L, Zhang ZM, Li H (2013) Stress reactivity and emotional recovery: Individual differences in sense of coherence. Journal of Psychological Science 36: 71-75.

26. Li J, Sun LY, Yan L (2015) Study on correlation and influencing factors of sense of coherence and life quality among breast cancer patients. Occupy and Health: 31: 1680-1684.

27. Wang ML, Liu JE, Su YL, Xue CC (2016) Experiences and insomniaassociated factors in Chinese breast cancer survivors: A qualitative study. Journal of Clinical Nursing 25(13-14): 1923-1930.

28. Smith TB, McCullough ME, Poll J (2003) Religiousness and depression: evidence for a main effect and the moderating influence of stressful life events. Psychological Bulletin 129: 614-636.

29. Gao Y (2014) The research about the social work intervening interpersonal barriers in the elderly living alone - talking the elderly living alone of Y community in Nanjing as a case. Naijing, Nanjing Agricultural University.

30. Chen Y (2017) Comparison of health status, social support and quality of life between the elderly living alone and non-living alone in Shanghai. Chinese Journal of Gerontology 37: 6211-6214.

31. Zhao HY, Sun SJ, Xun LM (2015) The correlation between selfmanagement behavior and psychological coherence in patients with type 2 diabetes mellitus. Modern Clinical Nursing 14(2): 13-16.

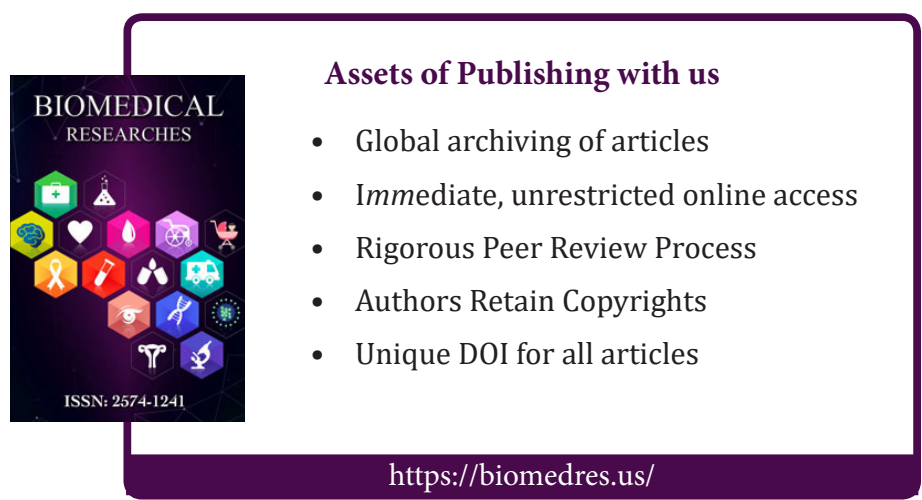

